2008-09

\title{
Impact of environmental production
} conditions on productivity and efficiency:

\section{A case study of wheat farmers in Bangladesh}

Rahman, Sanzidur

http://hdl.handle.net/10026.1/4026

10.1016/j.jenvman.2007.07.019

Journal of Environmental Management

Elsevier BV

All content in PEARL is protected by copyright law. Author manuscripts are made available in accordance with publisher policies. Please cite only the published version using the details provided on the item record or document. In the absence of an open licence (e.g. Creative Commons), permissions for further reuse of content should be sought from the publisher or author. 


\title{
Impact of Environmental Production Conditions on Productivity and
}

\section{EFFiciency: A CaSe Study of Wheat Farmers in Bangladesh}

\section{Sanzidur Rahman ${ }^{1}$}

School of Geography, Faculty of Social Science and Business, University of Plymouth Drake Circus, Plymouth, PL4 8AA, United Kingdom, Phone: +44-1752-238411, Fax: +441752-233054, E-mail: srahman@plymouth.ac.uk

\section{Kamrul Hasan}

On-Farm Research Division (OFRD), Bangladesh Agricultural Research Institute (BARI), Gazipur - 1701, Bangladesh, E-mail: khasan41@yahoo.com

\begin{abstract}
Environmental conditions significantly affect production, but are often ignored in studies analysing productivity and efficiency leading to biased results. In this study, we examine the influence of selected environmental factors on productivity and efficiency in wheat farming in Bangladesh. Results reveal that environmental production conditions significantly affect the parameters of the production function and technical efficiency, as well as correlates of inefficiency. Controlling for environmental production conditions improves technical efficiency by 4 points $(\mathrm{p}<0.01$ ) from $86 \%$ to $90 \%$. Large farms are more efficient relative to small and medium sized farms $(\mathrm{p}<0.01$ and 0.05$)$, with no variation among regions. Policy implications include, soil fertility improvement through soil conservation and crop rotation, improvement in managerial practices through extension services and adoption of modern technologies, promotion of education, strengthening the research-extension link, and development of new varieties that have higher yield potential and are also suitable for marginal areas.
\end{abstract}

Keywords: Stochastic production frontier, environmental conditions, wheat, Bangladesh

\footnotetext{
${ }^{1}$ Corresponding author.
} 


\section{Impact of Environmental Production Conditions on Productivity and}

\section{EFFiciency: A CASE STUdy OF Wheat FARMers in BANGLADESH}

\section{Introduction}

Agriculture is characterized by its environmental, behavioural, and policy dimensions (Clapham, 1980). Agricultural intensification, particularly the adoption of modern agricultural technology (e.g., chemical fertilizers, pesticides, etc.), is often blamed for contamination of water, loss of genetic diversity and deterioration of soil quality (Pretty, 1995). However, some of the most significant environmental problems in resource poor areas, such as, soil degradation, biocide resistance in pests, adverse weather, can in turn affect agricultural production systems directly as well (Clapham, 1980). Farmers' production performance does not only depend on the physical resources and technology available to them, but also on existing environmental production conditions. On the one hand, Schultz's (1964) hypothesis claims that small farmers are rational and economically efficient given their level of resources and technologies. On the other hand, studies examining farming efficiency in developing countries refute the validity of Schultz's thesis and place production efficiency levels within a range of $60-82 \%$ irrespective of crop types and regions (e.g., Rahman, 2003; Coelli et al., 2002; Wang et al., 1996; Battese and Coelli, 1995; Ali and Flinn, 1989). Sherlund et al., (2002) claim that the prevalence of inefficiency among small farmers may partly be due to the consistent omission of variables representing environmental production conditions in the myriad of efficiency studies conducted over the past three decades. They demonstrate three consequences arising from omission of potentially relevant environmental variables. The first consequence is the omitted variable bias, because the environmental variables are arbitrarily omitted. The second consequence is that the omitted variable bias is absorbed in the composite error $(\mathrm{v}-\mathrm{u})$ and hence carried on to the efficiency score which is computed from the non-negative $u$ term. The third and final consequence is 
that the determinants of inefficiency are regressed on an already biased estimate of technical efficiency score providing biased results (for details, see Sherlund et al., 2002).

In this study, we adopt the framework of Sherlund et al., (2002) to examine the impact of environmental production conditions on the performance of wheat production in Bangladesh. There are two reasons for adopting this framework. The first reason is that wheat production is gaining momentum in Bangladesh and the crop is relatively more sensitive to variations in environmental conditions as well as managerial factors as compared to rice production. The second reason is that, production environment differ largely between Cote d'Ivoire and Bangladesh in terms of topography, climate, land and soil conditions. Therefore, adoption of this framework provides an opportunity to evaluate performance of wheat production using a broader framework, as well as corroborate or contrast the findings of Sherlund et al., (2002), as it is applied to a different crop produced in a different production environment. Furthermore, in order to explain efficiency differentials among farmers, we utilize an elaborate set of managerial variables that are unique and critical in wheat production, but have not been reported in the existing literature on efficiency studies.

\section{Wheat in Bangladesh}

Bangladesh, traditionally a food deficit country dominated by rice production, also depended on wheat imports immediately after becoming an independent nation in 1971 which continued well into the late 1980s. This injection of wheat through imports gradually resulted in a change in dietary habits. As a result, wheat consumption now became an important supplement of rice. Also, wheat acreage now ranks second after rice area. The wheat area increased from 126,000 ha in 1971 to 832,000 ha in 2000 resulting in an increase in production from 103,000 tons to 1.84 million tons during the same period. Yield level also grew at an estimated $2.6 \%$ per annum increasing from $860 \mathrm{~kg} / \mathrm{ha}$ in 1971 to $2.2 \mathrm{t} / \mathrm{ha}$ in 2000 . According to the Bangladesh Soil Survey report, an estimated 3.1 million hectares are 
suitable for wheat (Hossain, 1985). During the early 1990s, a comprehensive review of food policy in Bangladesh dismissed wheat as a competitive crop in terms of economic and social profitability (Mahmud et al., 1994). However, it was later realised that wheat provides highest returns in non-irrigated zones and in areas that are unsuitable for Boro rice (dry winter irrigated rice) and represents the most efficient use of domestic resources when inputs and outputs are assigned economic prices (Morris et al., 1996). One unique feature of wheat in Bangladesh is $100 \%$ adoption of modern varieties as opposed to rice. Despite four decades of policy designed to increase the diffusion of modern rice technology, only $61 \%$ of the rice area is currently planted with modern varieties. Also, the use rate of modern inputs in wheat production is very high. For example, all our sample farmers used chemical fertilizers and supplementary irrigation. Nevertheless, OFRD (2001) reports that there is still a yield gap of $41-61 \%$ between farmers' practice and recommended package of the research station. Wheat yield with recommended package is $3.2 \mathrm{t} / \mathrm{ha}$ whereas actual production at farm level varies between 1.3 to $1.9 \mathrm{t} / \mathrm{ha}$. Nevertheless, best practice farmers can produce $2.8 \mathrm{t} / \mathrm{ha}$ when compared with $1.9 \mathrm{t} / \mathrm{ha}$ by the average farmer, thereby, revealing a 29\% yield gap (Hasan, 2005). Such a yield gap between best practice farmers and average farmers amounts to a loss of $25 \%$ of gross margin (Tk. $9875 /$ ha or US $\$ 169 /$ ha). Therefore, considerable scope exists to improve the productivity performance of the average farmers. One way to assess the extent of such scope is to empirically estimate technical efficiency in wheat production and its determinants. Studies on wheat efficiency in Bangladesh are highly limited (e.g., Karim et al., 2003), when compared with other developing countries, such as Pakistan (Battese et al., 1996), India (Singh, et al, 2004) and Iran (Bakhsoodeh and Thomson, 2001).

The paper proceeds as follows. The next section describes the analytical framework, study areas and the data. Section 3 presents the results. The final section concludes and draws policy implications. 


\section{Research Methodology}

\section{$\underline{\text { Analytical framework }}$}

The stochastic production frontier approach, developed by Aigner et al., (1977), is utilized in this study. We extend the framework and include variables representing environmental production conditions in addition to physical inputs to explain productivity performance as described by Sherlund et al, (2002). The stochastic production frontier for the $i$ th farmer is written as:

$Y_{i}=f\left(X_{i}, W_{i}\right)-u_{i}+v_{i}$

where $Y_{i}$ is the output, $X_{i}$ is the vector of physical inputs, $W_{i}$ is the vector of relevant environmental variables that control production conditions, $v_{i}$ is assumed to be independently and identically distributed $N\left(0, \sigma_{v}^{2}\right)$ two sided random error, independent of the $u_{i}$; and the $u_{i}$ is a non-negative random variable $\left(u_{i} \geq 0\right)$, associated with inefficiency in production which is assumed to be independently distributed as truncation at zero of the normal distribution with mean $-Z_{i} \delta$, and variance $\sigma_{u}^{2}\left(\mid N\left(-Z_{i} \delta, \sigma_{u}^{2} \mid\right)\right.$, where $Z_{i}$ are the correlates of inefficiencies on farm $i$. In this formulation, output is assumed to be strictly monotonically increasing in both physical inputs as well as environmental conditions. Most studies in the literature typically estimate:

$$
Y_{i}=g\left(X_{i}, W_{i}^{*}\right)-u_{i}^{*}+v_{i}^{*}
$$

where $W_{i}^{*} \subseteq W_{i}$, which omits some or all of the elements of $W_{i}$, and, therefore, results in biased estimates of the parameters of the production function, overstatement of technical inefficiency, as well as biased correlates of inefficiency (Sherlund et al., 2002).

In determining the predictors of production efficiency, we use the single stage approach proposed by Battese and Coelli (1995) wherein the technical inefficiency parameter is related to a vector of farm-specific managerial and household characteristics subject to statistical error, 
such that:

$u_{i}=Z_{i} \delta+\zeta_{i} \geq 0,(3)$

where, $Z_{i}$ are the farm-specific managerial and household characteristics and the error $\zeta_{i}$ is distributed as $\zeta_{i} \sim N\left(0, \sigma_{\zeta}^{2}\right)$. Since $u_{i} \geq 0, \zeta_{i} \geq-Z_{i} \delta$, so that the distribution of $\zeta_{i}$ is truncated from below at the variable truncation point, $-Z_{i} \delta$.

The production efficiency of farm $i$ in the context of the stochastic frontier production function is defined as:

$$
E F F_{i}=E\left[\exp \left(-u_{i}\right) \mid \xi_{i}\right]=E\left[\exp \left(-\delta_{0}-\sum Z_{i} \delta \mid \xi_{i}\right)\right.
$$

where $E$ is the expectation operator. This is achieved by obtaining the expressions for the conditional expectation $u_{i}$ upon the observed value of $\xi_{i}$, where $\xi_{i}=\mathrm{v}_{\mathrm{i}}-\mathrm{u}_{\mathrm{i}}$. The method of maximum likelihood is used to estimate the unknown parameters, with the stochastic frontier and the inefficiency effects functions estimated simultaneously. The likelihood function is expressed in term of the variance parameters, $\sigma^{2}=\sigma_{v}{ }^{2}+\sigma_{u}{ }^{2}$ and $\gamma=\sigma_{u}{ }^{2} / \sigma^{2}$ (Battese and Coelli, 1995).

\section{Selection of the study area and sample farmers}

Wheat is cultivated almost all over the country, though the intensity of planted area and land suitability are not equal in all regions. Therefore, we computed a wheat area index for each greater district ${ }^{2}$. The wheat area index for the $j$ th district is expressed as:

$W I_{j}=\left(\right.$ Area $\left._{j} / G C A_{j}\right) * 100$

where $W I$ is the wheat area index, Area is the wheat area and GCA is the gross cropped area. Based on this index, wheat growing regions were classified into three levels of intensity: high intensity $(W I>8.0)$, medium intensity $(4.01<W I<8.0)$, and low intensity areas $(W I<4.0)$.

\footnotetext{
2 Although there are 64 districts in Bangladesh, most secondary data are still reported at the level of these 21 former greater districts.
} 
A multistage sampling procedure was adopted to select the sample farmers. First, three wheat growing regions (two from high intensity areas - Dinajpur and Rajshahi, and one from medium intensity areas - Jamalpur) were selected purposively ${ }^{3}$. The selected three districts $/$ regions ${ }^{4}$ together cover $31 \%$ of the total wheat area of the country (Table 1 ). Also, each selected district belonged to different agro-ecological zones (AEZ) of Bangladesh, namely, AEZ-3, AEZ 11 and AEZ-9, respectively5. Dinajpur is located in the north-west, Rajshahi in the mid-west and Jamalpur in the mid-north of Bangladesh. In the second stage, one upazila (sub-district) from each district and one union from each upazila were selected at random. Next, three mouzas (one from each union) were selected at random for primary data collection from farm households. However, due to an insufficient number of households in one mouza, a fourth mouza was also selected at random to fulfil the required sample size. In the third stage, a number of steps were followed to select the households to ensure a high level of representation. At first, a sampling frame of wheat growing holdings was constructed with the assistance of village leaders, record book at the union council office and other key informants. The list included the names of household heads and their land holdings in the selected mouzas. These farm holdings were then stratified into three standard farm-size categories commonly adopted in Bangladesh (e.g., Hossain, 1989). Then, a total of 293 wheat producing households were selected following a stratified random sampling procedure. Two sets of structured questionnaires were administered. These questionnaires were pre-tested prior to finalization. The survey covered wheat growing period from November 2003 to April

\footnotetext{
3 The low intensity area is excluded because it is assumed that wheat production has limited potential in these districts.

${ }^{4}$ In this study the term district and region are used interchangeably to emphasize the large spatial variation between our study areas.

${ }^{5}$ There are a total of 29 agro-ecological zones which cut across many of the 21 greater districts/regions.
} 
2004.

\section{[INSERT TABLE 1 HERE]}

\section{The empirical model}

The general form of the Cobb-Douglas stochastic production frontier function is used $^{6}$. In order to determine the consequences of omitting environmental production conditions, we estimated the production frontier 'with' and 'without' the environmental variables. Hence, the conventional specification which omits the $W_{i}$ variables (as in equation 2) is written as:

$\ln Y_{i}=\alpha_{0}+\sum_{j=1}^{8} \alpha_{j}^{*} \ln X_{i j}+\sum_{j=1}^{2} \beta_{j} D_{i j}+\sum_{m=1}^{2} \tau_{m} R_{i m}+v_{i}^{*}-u_{i}^{*}$

and

$u_{i}^{*}=\delta_{0}^{*}+\sum_{d=1}^{13} \delta_{d}^{*} Z_{i d}+\zeta_{i}^{*}$

where $Y_{i}$ is the wheat output (including grain equivalent of straw output); $X_{i j}$ is $j$ th input for the ith farmer; $D_{i j}$ are the dummy variables used to account for the zero values of input use and have the value of 1 if the $j$ th input used is positive and zero otherwise $; R_{i m}$ is the dummy variable for districts, $v_{i}$ is the two sided random error, $u_{i}$ is the one sided half-normal error, $\ln$ natural logarithm, $Z_{i d}$ variables representing managerial and socio-economic characteristics of the farm to explain inefficiency, $\zeta_{i}$ is the truncated random variable; $\alpha_{0}, \alpha_{j}, \beta_{j}, \tau_{m}, \delta_{0}$, and $\delta_{d}$ are the parameters to be estimated.

\footnotetext{
${ }^{6}$ We did not use the translog model because of the limited sample size and the large number of explanatory indicators. Moreover, Kopp and Smith (1980) suggest that the choice of functional form has a limited effect on technical efficiency. Consequently, the Cobb-Douglas specification is widely used in studies (e.g., Rezitis et al., 2002; Xu and Jeffrey, 1998).

${ }^{7}$ In this study, inputs that contain zero values for some observations are specified as $\ln \left\{\max \left(X_{j}, 1-D_{j}\right)\right\}$ following Battese and Coelli (1995).
} 
Similarly, the full specification including variables representing environmental production conditions (i.e., Equation 1) is written as:

$\ln Y_{i}=\alpha_{0}+\sum_{j=1}^{8} \alpha_{j} \ln X_{i j}+\sum_{j=1}^{2} \beta_{j} D_{i j}+\sum_{k=1}^{7} \varphi_{k} E_{i k}+\sum_{m=1}^{2} \tau_{m} R_{i m}+v_{i}-u_{i}$

and

$u_{i}=\delta_{0}+\sum_{d=1}^{13} \delta_{d} Z_{i d}+\zeta_{i}$

where, $E_{i k}$ are the environmental production condition variables, and $\varphi_{k}$ is the parameter to be estimated. All other variables as defined earlier.

A total of eight production inputs $(\mathrm{X})$, seven environmental production condition variables (E), and two regional dummies $(\mathrm{R})$ are used in the full specification, and 13 variables representing managerial and socio-economic characteristics of the farmer $(Z)$ are included in the inefficiency effects model as predictors of technical inefficiency in both short and full specifications. Table 2 presents the definitions, units of measurement, and summary statistics for all the variables.

\section{[INSERT TABLE 2 HERE]}

\section{Results}

From the information provided in Table 2, we can see that average farm size is very small (0.13 ha). Land type is in the suitable range whereas soil type is of average quality. Variables representing environmental production conditions are non-zero $(p<0.01)$. The average age of the farmers is 47 years with 16 years of experience in growing wheat, education is less than five years, $61 \%$ used mechanical power services, extension link is relatively high (13.4 times in a year), farmers are exposed to at least two sources of agricultural information, and only $14 \%$ received training on wheat production in the past 5 years.

\section{$\underline{\text { Environmental production conditions and production inputs }}$}

The assumption underlying the inclusion of environmental production conditions in 
estimating the parameters of the production frontier is that they are exogenously determined. Furthermore, if these variables are asymmetrically distributed, then their omission will lead to upward bias in the estimates of firm specific technical inefficiency. The assumption of exogeneity of these variables can be challenged, as weed and pesticide infestations or poor soil fertility could be improved in the long run by adding more labour or by adopting soil conservation measures. However, the production scenario in Bangladesh is dominated by usufruct tenurial arrangement wherein tenants have little or no incentive to invest in conservation measures since benefits accruing from such activities are simply unrealizable and uncertain due to high insecurity of tenure. On the other hand, weather (e.g., storm, flood, drought, rainfall, etc.) is truly exogenous, and the variables 'soil types' and 'land types' are quasi-fixed in nature. So, the suite of variables chosen to control for environmental production conditions includes the truly exogenous (e.g., weather), quasi-fixed characteristics (e.g., soil types and land types) as well as combinations of exogenous shocks and managerial response (e.g., pest and weed infestation). Table 3 presents the results of the correlation between production inputs and the environmental variables. The strength of correlation is relatively weak but half of the relationships are non-zero $(p<0.01$ to $p<0.10)$. Sherlund et al., (2002) also reported similar strong correlation, thereby making a valid case for the need to control for environmental production conditions while examining farmers' production performances.

[INSERT TABLE 3 HERE]

\section{Productivity effects of environmental production conditions}

Parameter estimates for both short and full specification are reported in Table 4 using the Maximum Likelihood Estimation (MLE) procedure in STATA Version 8 (STATA Corp, 2003). First we checked the sign of the third moment and the skewness of the Ordinary Least Squares (OLS) residuals of the data in order to justify the use of the stochastic frontier 
framework (and hence the MLE procedure) $)^{8}$. The computed value of Coelli's (1995) standard normal skewness statistic (M3T) based on the third moment of the OLS residuals are -2.997 $(\mathrm{p}<0.001)$ and $-2.100(\mathrm{p}<0.013)$ tested against $\mathrm{H}_{0}$ : M3T $=0$ in both the short and the full model, respectively. In other words, the null hypothesis of no inefficiency component is strongly rejected for both models and, therefore, the use of the stochastic frontier framework is justified. The result of the Likelihood Ratio (LR) test of $\gamma$ reported in Table 5 also strongly suggests presence of technical inefficiency.

The statistical superiority of the full specification is apparent from the LR test statistic of $60.04(p<0.000)$ tested against the $\chi^{2}(7)$ distribution based on Log Likelihood values reported in Table 4. Two of the production input variables, herbicides and cow-dung, recorded large numbers of zero observations, and therefore, corrected with dummy variables as mentioned in Footnote 7. As expected, land is the most dominant input followed by fertilizers, labour, irrigation, and animal/mechanical power services in both specifications. The test of hypotheses that environmental variables are jointly zero in the full specification is rejected indicating environmental production conditions significantly affect productivity as expected $^{9}$ (Table 5). Poor land types, delay in sowing and poor soil quality significantly reduce productivity. The omission of variables representing environmental production conditions also affects estimates of the production function itself. For example, the output elasticity of wheat increases by $4.9 \%$ than it is under conventional specification ${ }^{10}$. On the other hand the elasticity of fertilizers declines by $27.7 \%$. Once one controls for the

\footnotetext{
${ }^{8}$ In the stochastic frontier framework, the third moment is also the third sample moment of the $u_{i}$. Therefore, if it is negative, it implies that the OLS residuals are negatively skewed and technical inefficiency is present.

9 The LR test reported earlier also effectively tested the same hypothesis.

${ }^{10}$ Since the Cobb-Douglas model is used, the parameter estimates of the production inputs can be directly read as production elasticities.
} 
environmental production conditions, the role of fertilizer input becomes less responsive to productivity increases. Sherlund et al., (2002) also reported a high positive response of rice output by $20 \%$ and drastic fall in inputs of labour by almost $70 \%$ when they controlled for environmental production conditions for Cote d'Ivoire rice farmers. However, the hypothesis of constant returns to scale in wheat production cannot be rejected in both specifications (Table 5) implying that wheat output can be increased proportionately at the same rate with increases in input quantities. It also implies that the wheat farmers are operating at an optimal scale. This finding is encouraging because in contrast, decreasing returns to scale is often reported for rice production in Bangladesh (e.g., Wadud and White, 2000; Asadullah and Rahman, forthcoming), implying that the rice farmers are not operating at an optimal scale.

\section{[INSERT TABLES 4 and 5 HERE]}

\section{Production efficiency}

Controlling for environmental production conditions improves technical efficiency by 4 points $(p<0.01)$, thereby validating the claim that inefficiency is overstated when these variables are omitted (Table 6). The main improvement is at the lower end of the distribution (Figure 1). For example, the minimum technical efficiency score under the short specification is $55.2 \%$ while under the full specification it is $64.9 \%$, a $17.5 \%$ improvement (Table 6 ). In the short specification, $22.5 \%$ of farmers are operating below the $70 \%$ efficiency level, whereas under the full specification the figure falls to only $8.2 \%$. Sherlund et al, (2002) reported much larger improvements in mean technical efficiency for rice farmers from $36 \%$ to $77 \%$ when they controlled for environmental production conditions. The mean technical efficiency level in wheat production is estimated at $90 \%$ which implies that production can be increased by $10.6 \%[\{(0.902-1.00) / 0.902\} * 100]$ with efficiency improvements. The mean estimate exactly matches with that of Karim et al., (2003) and is also comparable to estimates in other developing countries. For example, technical efficiency in wheat production varies between 
$57.0 \%-78.9 \%$ in Pakistan (Battese et al., 1996), 81.0 - 93.4\% in India (Singh, et al, 2004)

and $91.0-93.0 \%$ in Iran (Bakhsoodeh and Thomson, 2001), respectively.

\section{[INSERT TABLE 6 and FIGURE 1 HERE]}

\section{Efficiency effects of environmental production conditions}

The omission of the environmental production conditions also significantly affects the correlates of inefficiency (see lower panel of Table 4). Although, the parameter estimates are broadly similar across both regressions, the effects are intuitively more precise under the full specification. The hypotheses that the managerial variables are jointly zero are rejected for both specifications (Table 5). Technical efficiency in wheat farming is highly sensitive to managerial factors. For example, failure to sow on time, delay in the first application of fertilizer and selection of poor quality seeds significantly decrease efficiency. On the other hand, education and agricultural information sources significantly increase efficiency. The expected effect of training in increasing efficiency is also consistent with theory but the coefficient is not significantly different from zero. Use of modern technology, i.e., mechanical power services instead of animal power, significantly improves efficiency.

Efficiency increases with size of operation. The middle panel of Table 6 provides information on the mean technical efficiency scores by farm-size categories. It is obvious from Table 6 that large farms operate at the highest level of efficiency when compared with medium and small farms. The reason that large farmers are more efficient in wheat farming is due to better education, higher level of modern technology adoption, better managerial practices, and extension facilities (Table 7). Table 7 clearly shows that the use of mechanical power services, mechanical ploughing and irrigation are higher for large farmers. The timing of fertilizer application is nearly optimal, although first weeding is relatively late. Also, $22 \%$ of large farmers received training on wheat production over the past 5 years. The mean education level is well above primary level ( 7.5 years of schooling) with 18.1 years of 
experience in wheat production. All these factors have contributed to a significantly higher level of technical efficiency of large farmers when compared with medium and small farmers. The computed F-test statistics prove the results (Table 7).

\section{[INSERT TABLE 7 HERE]}

\section{Conclusions and policy implications}

The present study examined the impact of environmental production conditions on the production performance of wheat producers in Bangladesh. The environmental production conditions, within which the farmer operates, are considered vital but are often arbitrarily omitted in productivity and efficiency studies, resulting in biased estimates of the production parameters, efficiency scores and correlates of inefficiency. Our results demonstrate the validity of this claim for Bangladeshi wheat farmers. Poor land type, poor soil fertility and delay in sowing results in significant production loss. Controlling for environmental production conditions improves technical efficiency by 4 points $(\mathrm{p}<0.01)$ from $86 \%$ to $90 \%$. Farmers' managerial practices, particularly, timely sowing and fertilizer application, use of mechanical power, higher education and diverse sources of agricultural information, all significantly improve efficiency. Nevertheless, scope to raise wheat production remains limited with the existing set of varieties and technologies because farmers have already adopted $100 \%$ percent of popular modern varieties and are also producing at a high level of efficiency $(90 \%)$.

The results of our study has significant policy implications as it demonstrates the need to evaluate farmers' production performance using an extended framework of analysis, that takes into account the environmental production conditions within which farmers have to operate. Otherwise, the upward bias of inefficiency measures, widely reported in the literature, would lead to a redirection of scarce resources to less than optimal uses. Also, in modelling predictors of inefficiency, it is important to use an elaborate set of variables, 
particularly managerial variables unique to each crop studied, so that management factors that directly affect production performance can be addressed through policy redressing.

Furthermore, based on the results of our study, a number of specific policy implications can be drawn. First, soil fertility improvement seems essential to raise productivity. This may be addressed through adopting soil conservation practices and/or improving crop rotation practices (e.g., including soil health enhancing crops, such as pulses and oilseeds, in the system). Of the nine total cropping patterns observed among the sample farmers, most followed rice-based cropping. Only two patterns included jute in the system and none included any pulse or oilseed crops, which is potentially highly detrimental to soil health in the long run. Second, is the improvement in managerial practices (e.g., timely sowing and fertilizer application) and the use of modern technology (e.g., mechanical power services and irrigation). These can be addressed through strengthening agricultural extension services and improvements in rural infrastructure. Third, promotion of education above primary level for the farming population seems crucial. Our results show that the large farmers who are educated above primary level and have relatively higher access to modern resources, services and skills are performing significantly better. Asadullah and Rahman (forthcoming) also noted that farmers who complete secondary schooling enjoy significant efficiency gains. Fourth, is to improve existing research-extension link. Currently, new varieties that are developed remain confined at the research stations. Dominance of only one variety at the farm-level which was released 21 years ago ${ }^{11}$, clearly points towards the need to develop the research-extension link. Finally, our study shows that poor land type significantly reduces productivity. Therefore, research effort should be geared towards developing varieties that are suitable for marginal areas. Evidence suggests that wheat production in marginal

\footnotetext{
11 Although 24 modern varieties of wheat have been released since 1974 (including three in 2005), 'Kanchan' released in 1983, remains the most popular choice. In fact, 94\% of our sample farmers used only 'Kanchan'.
} 
lands accounts for $25 \%$ of global production and that research innovation has led to significant improvement in yield growth in these areas, particularly in drought and high temperature environments (Lantican et al, 2003). The challenges to realize all of these policy options are formidable. However, a boost in wheat production could significantly curb dependence on rice as the main staple in Bangladeshi diet, which is a goal worth pursuing.

\section{Acknowledgements}

The paper was presented at the $81^{\text {st }}$ annual conference of the Agricultural Economics Society (AES) held at the Reading University, UK during April 2 - 4, 2007. The authors thank Noel Russell, Derek Shepherd and the anonymous referees for their constructive comments which improved the paper considerably. All caveats remain with the authors.

\section{References}

Aigner, D.J., Lovell, C.A.K., Schmidt, P. 1977. Formulation and estimation of stochastic frontier production function models. Journal of Econometrics, 6: $21-37$.

Ali, M., and Flinn, J.C. 1989. Profit efficiency among Basmati rice producers in Pakistan Punjab. American Journal of Agricultural Economics, 71, 303 - 310.

Asadullah, M.N., Rahman, S. forthcoming. Farm productivity and efficiency in rural Bangladesh: the role of education revisited. Applied Economics.

Bakhsoodeh, M., Thomson, K.J. 2001. Input and output technical efficiencies of wheat production in Kemran, Iran. Agricultural Economics, 24: $307-313$.

Battese, G.E., Coelli, T.J. 1995. A model for technical inefficiency effects in a stochastic frontier production function for panel data, Empirical Economics, 20, 325-332.

Battese, G.E., Malik, S.J., Gill, G.A. 1996. An investigation of technical inefficiencies of production of wheat farmers in four districts of Pakistan. Journal of Agricultural 
Economics, 47: $37-49$.

BBS, 2000. Statistical Yearbook of Bangladesh 1999. Bangladesh Bureau of Statistics, Dhaka, Bangladesh.

Clapham, W.B. 1980. Environmental problems, development, and agricultural production systems. Environmental Conservation, 7: $145-152$.

Coelli, T.J. 1995. Estimators and hypothesis tests for a stochastic frontier function: a MonteCarlo analysis. Journal of Productivity Analysis, 6, $247-268$.

Coelli, T., Rahman, S., Thirtle, C. 2002. Technical, allocative, cost and scale efficiencies in Bangladesh rice cultivation: a non-parametric approach. Journal of Agricultural Economics, 53: $607-626$.

Hasan, M.K. 2005. Yield and benefit gaps in wheat production: comparison between two farmer management practices. Seminar on Higher Agricultural Education and Research in Bangladesh: Prospects and Challenges. Bangladesh Agricultural University, Mymensingh.

Hossain, M. 1989. Green Revolution in Bangladesh: Impact on Growth and Distribution of Income. University Press Limited, Dhaka.

Hossain, A.B.S. 1985. Wheat production in Bangladesh: its constraints and research priorities. In Wheat for more tropical environments. Proceedings of the International Symposium held September 24-28, 1984 at CIMMYT, Mexico.

Karim, M.R., Ahmed, M., Islam, M.N., Islam, M.R. 2002. Efficiency of irrigated wheat production on the high Ganges floodplain soils of Bangladesh. Thai Journal of Agricultural Science, 32: 135 - 144 .

Kopp, R.J. and Smith, V.K. 1980, Frontier production function estimates for steam electric generation: a competitive analysis. Southern Economic Journal, 47, 1049-1059.

Lantican, M.A., Pingali, P.L., Rajaram, S. 2003. Is research on marginal lands catching up? The 
case of unfavourable wheat growing environments. Agricultural Economics, 29: 353 361.

Mahmud, W., Rahman, S.H., Zohir, S. 1994. Agricultural growth through crop diversification in Bangladesh. Food Policy in Bangladesh Working Paper \# 7. International Food Policy Research Institute, Washington, D.C., USA.

Morris, M., Chowdhury, N., Meisner, C. 1996. Economics of wheat production in Bangladesh. Food Policy, 21: $541-560$.

OFRD, 2001. Annual Report, 1999-2000. On-Farm Research Division. Bangladesh Agricultural Research Institute (BARI), Gazipur, Bangladesh.

Pretty, J.N. 1995. Regenerating agriculture: policies and practices for sustainability and selfreliance. Earthscan Publications, London, UK.

Rahman, S. 2003. Profit efficiency among Bangladeshi rice farmers. Food Policy, 28: 487 503.

Rezitis, A.N., Tsiboukas, C., and Tsoukalas, S. 2002, Measuring technical efficiency in the Greek agricultural sector. Applied Economics, 34, 1345-1357.

Schultz, T.W. 1964. Transforming traditional agriculture. Yale University Press, New haven, Connecticut, USA.

Sherlund, S.M., Barrett, C.B., Adesina, A.A. 2002. Smallholder technical efficiency controlling for environmental production conditions. Journal of Development Economics, 69: $85-101$.

STATA Corp, 2003. STATA Version 8. Stata Press Publications, College Station, Texas, USA.

Singh, G., Singh, S., Singh, J. 2004. Optimization of energy inputs in wheat crop in Punjab. Energy Conservation and Management, 45: 453 - 465.

Tadesse, B., Krishnamoorthy, S. 1997. Technical efficiency of paddy farms of Tamil-Nadu: 
an analysis based on farm size and ecological zones. Agricultural Economics, 16: 185 $-192$.

Wadud, A. and White, B., 2000, Farm household efficiency in Bangladesh: a comparison of stochastic frontier and DEA methods. Applied Economics, 32, 1665-1673.

Wang, J., Cramer, G.L., Wailes, E.J. 1996. Production efficiency of Chinese agriculture: evidence from Rural Household Survey data. Agricultural Economics, 15, 17 - 28.

Xu, X., Jeffrey, S.R., 1998. Efficiency and technical progress in traditional and modern agriculture: evidence from rice production in China. Agricultural Economics, 18, 157165. 


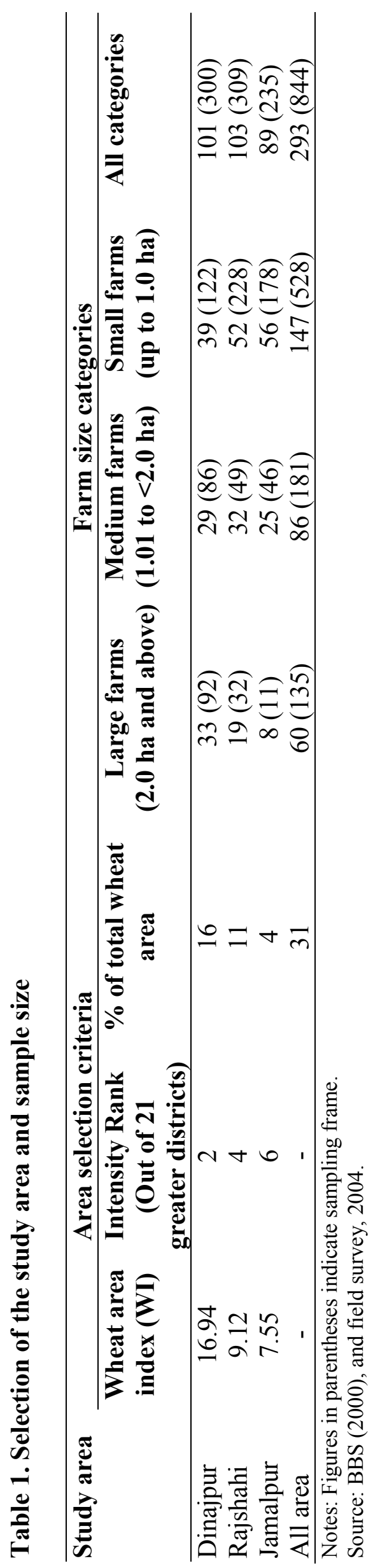




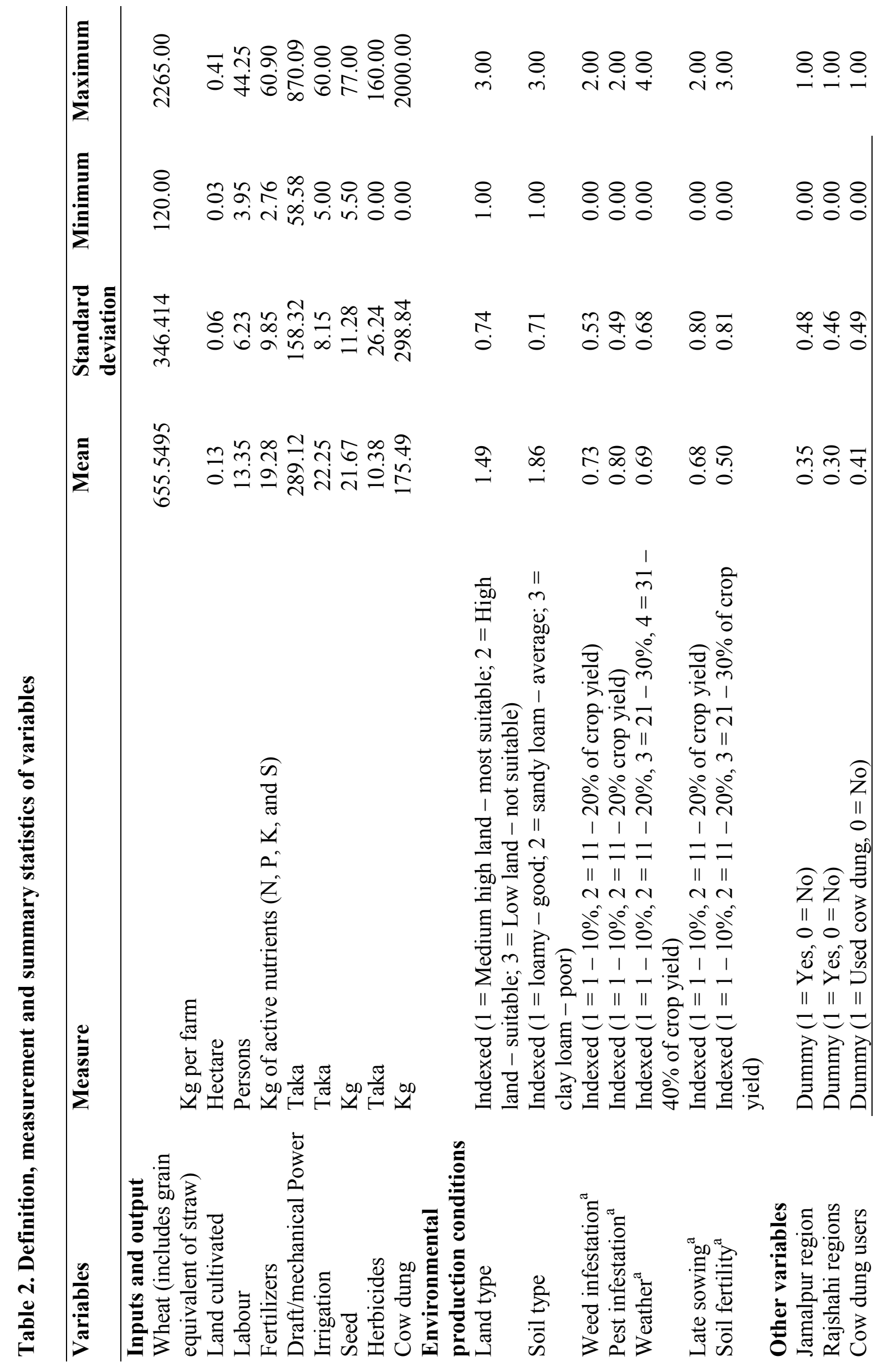




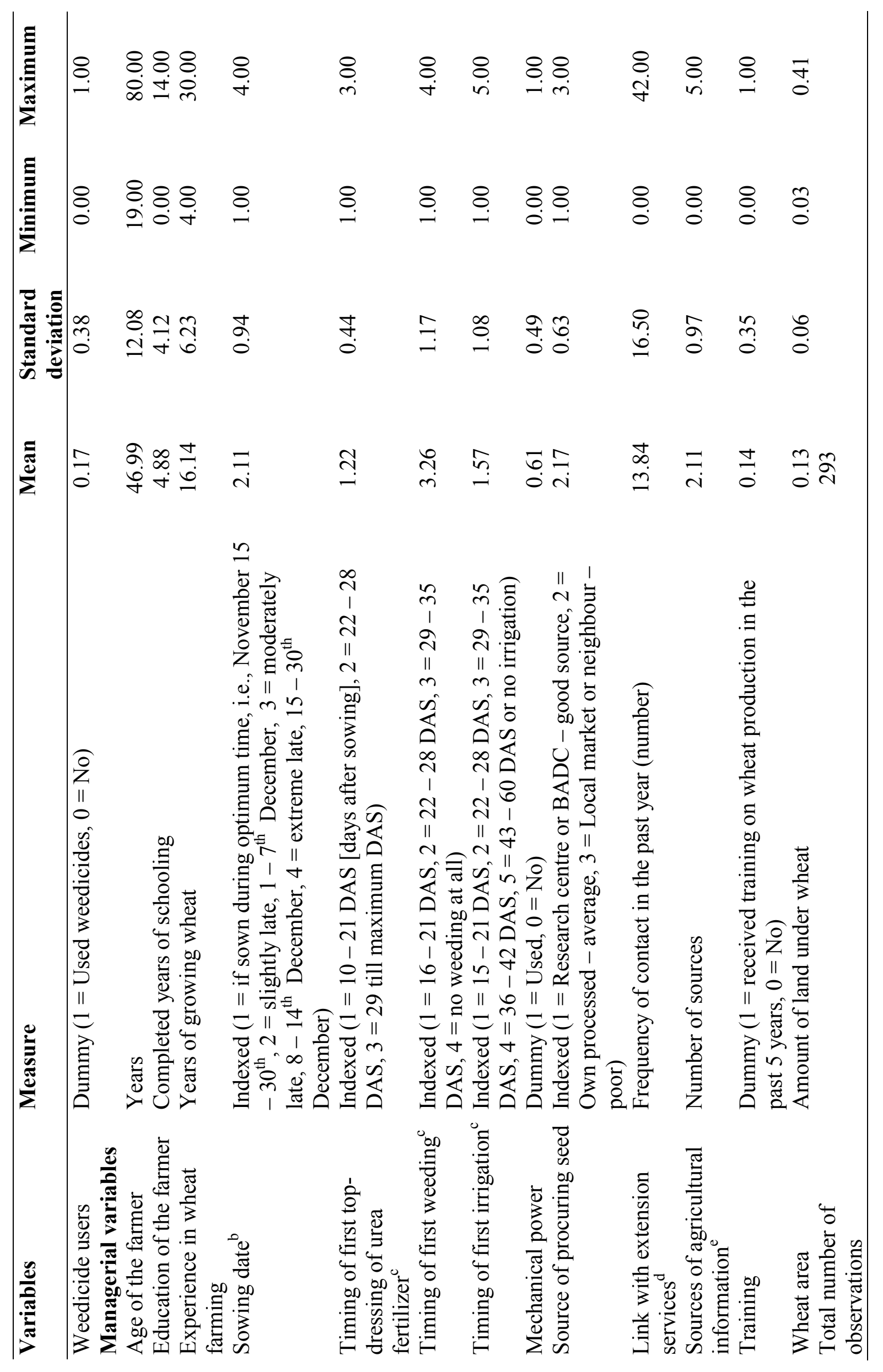




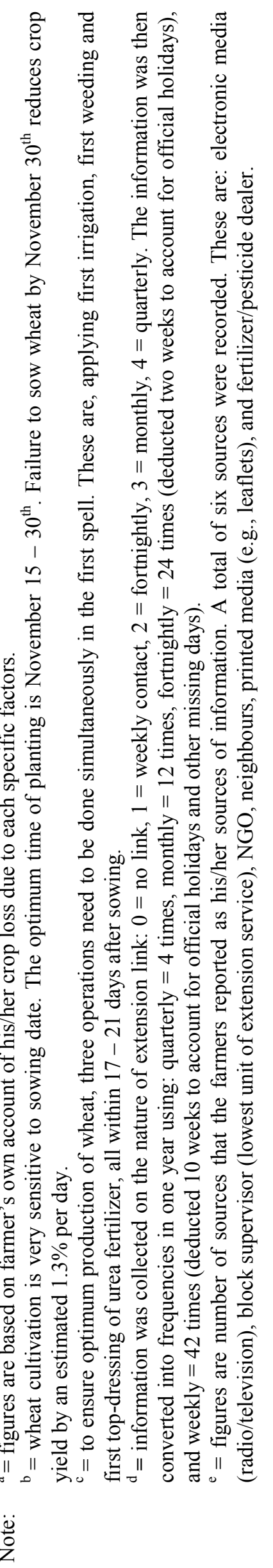




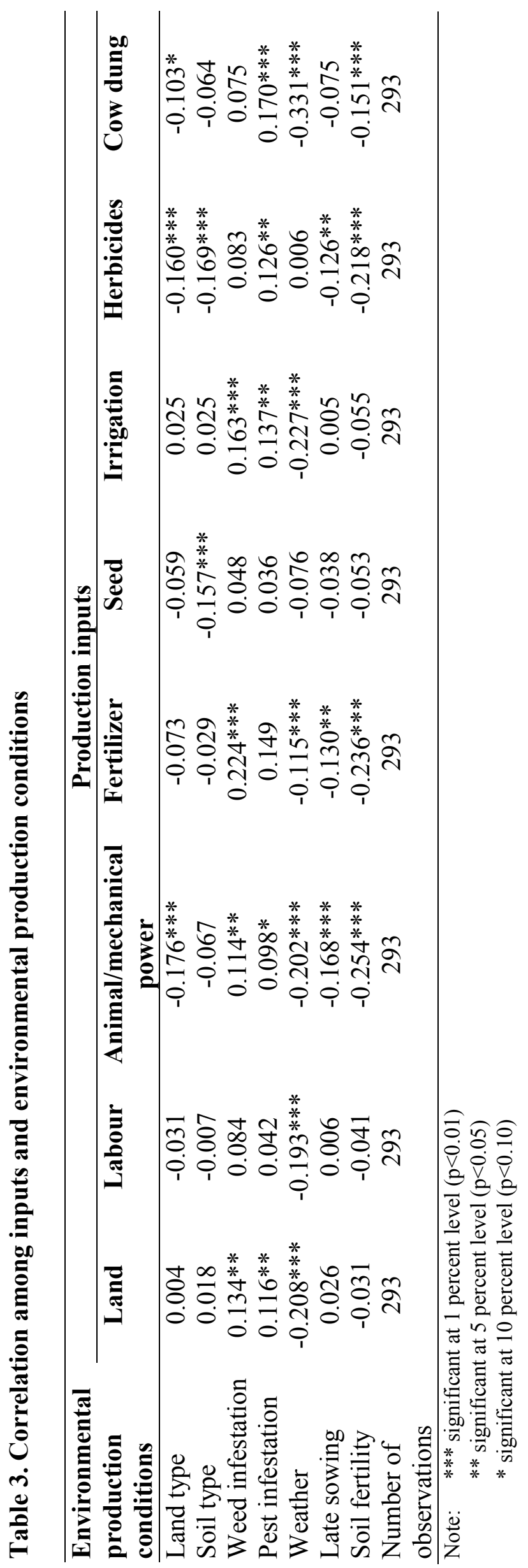




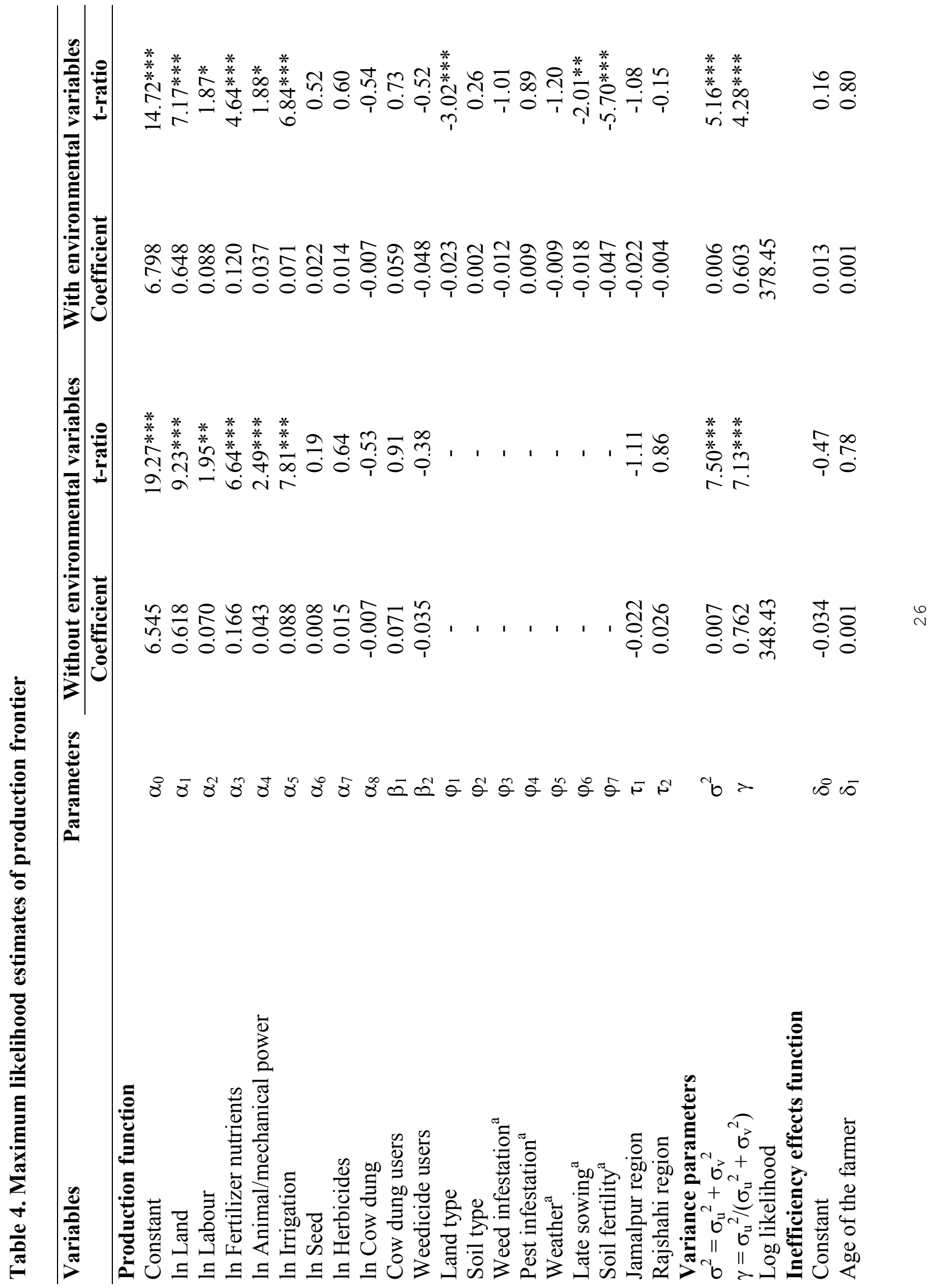




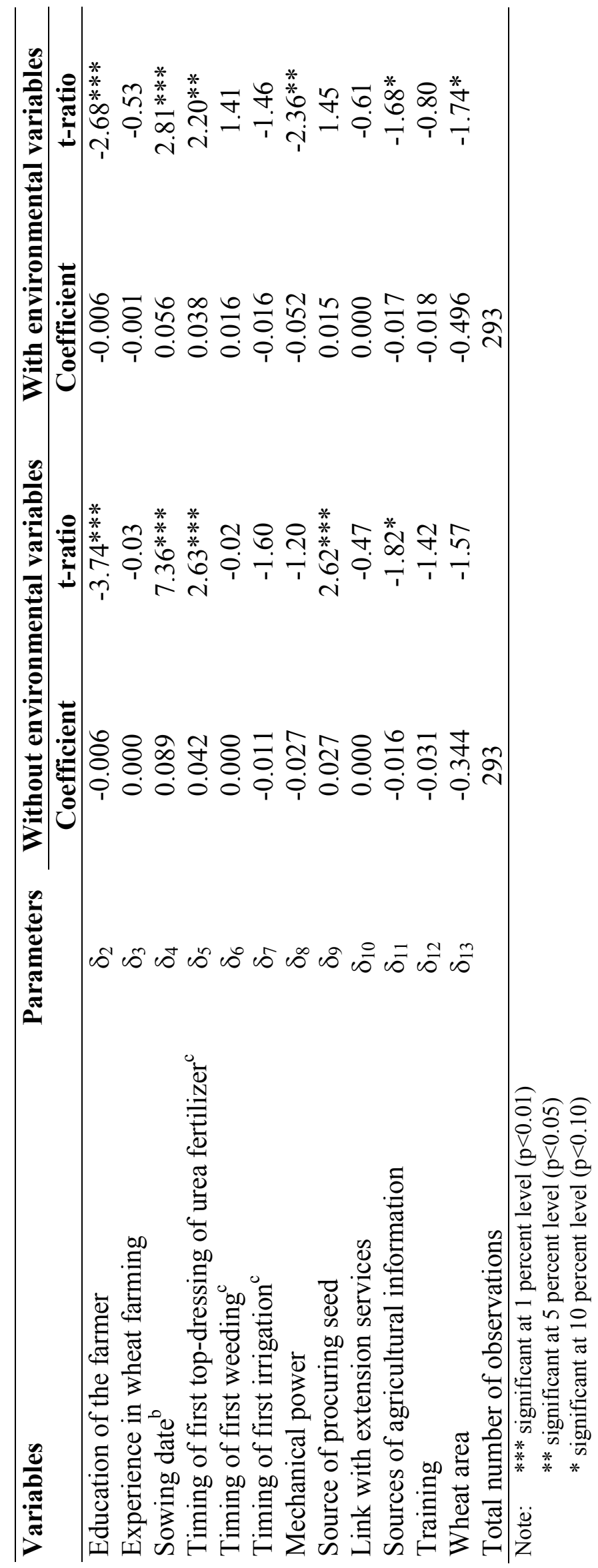


Table 5. Tests of hypotheses

\begin{tabular}{|c|c|c|c|c|c|}
\hline \multirow[t]{2}{*}{ Hypothesis } & \multirow{2}{*}{$\begin{array}{l}\text { Critical } \\
\text { value of } \\
\chi^{2}(v, 0.99)\end{array}$} & \multicolumn{2}{|c|}{$\begin{array}{c}\text { Without environmental } \\
\text { variables }\end{array}$} & \multicolumn{2}{|c|}{$\begin{array}{c}\text { With environmental } \\
\text { variables }\end{array}$} \\
\hline & & LR statistic & Decision & LR statistic & Decision \\
\hline $\begin{array}{l}\text { No effect of environmental } \\
\text { variables on productivity } \\
\left(\mathrm{H}_{0}: \varphi_{1}=\varphi_{2}=\ldots=\varphi_{7}=0\right)\end{array}$ & 18.48 & - & - & $69.10^{* * *}$ & Reject $\mathrm{H}_{0}$ \\
\hline $\begin{array}{l}\text { Presence of inefficiency } \\
\left(\mathrm{H}_{0}: \gamma=0\right)\end{array}$ & 6.64 & $7.13^{* * *}$ & Reject $\mathrm{H}_{0}$ & $4.27 * *$ & Reject $\mathrm{H}_{0}$ \\
\hline $\begin{array}{l}\text { No effect of managerial } \\
\text { variables on inefficiency } \\
\left(\mathrm{H}_{0}: \delta_{1}=\delta_{2}=\ldots=\delta_{13}=0\right)\end{array}$ & 27.69 & $100.52 * * *$ & Reject $\mathrm{H}_{0}$ & $40.78 * * *$ & Reject $\mathrm{H}_{0}$ \\
\hline $\begin{array}{l}\text { Constant returns to scale in } \\
\text { production } \\
\left(\mathrm{H}_{0}: \alpha_{1}+\alpha_{2}+\ldots+\alpha_{8}=1\right)\end{array}$ & 20.09 & 0.01 & Accept $\mathrm{H}_{0}$ & 0.04 & Accept $\mathrm{H}_{0}$ \\
\hline $\begin{array}{ll}\text { Note: } & \text { In testing }\left(\mathrm{H}_{0}: \gamma=0\right) \text { in } \mathrm{t} \\
& * * * \text { significant at } 1 \text { perce } \\
& * * \text { significant at } 5 \text { percer }\end{array}$ & $1(\mathrm{p}<0$. & & & & \\
\hline
\end{tabular}


Table 6. Technical efficiency estimates with and without environmental production condition variables

\begin{tabular}{lcc}
\hline Items & $\begin{array}{c}\text { Without environmental } \\
\text { production condition } \\
\text { variables }\end{array}$ & $\begin{array}{c}\text { With environmental } \\
\text { production condition } \\
\text { variables }\end{array}$ \\
\hline Efficiency levels & 0.68 & - \\
up to $60 \%$ & 5.12 & 0.68 \\
$61-70 \%$ & 16.72 & 7.51 \\
$71-80 \%$ & 38.22 & 34.81 \\
$81-90 \%$ & 39.26 & 57.00 \\
$91 \%$ and above & & \\
Mean efficiency by farm size & 0.898 & 0.935 \\
Large farms & 0.856 & 0.902 \\
Medium farms & 0.847 & 0.889 \\
Small farms & & 0.902 \\
Overall & 0.860 & 0.07 \\
Mean efficiency score & 0.09 & 0.649 \\
Standard deviation & 0.552 & 0.990 \\
Minimum & 0.989 & 0.042 \\
Maximum & & $(20.30)^{* * *}$ \\
t-test for difference in mean & & \\
efficiency score between alternative & & \\
models & & \\
\hline Note: Figure in parenthesis is the t-ratio. & & \\
$\quad * * *$ significant at 1 percent level $(\mathrm{p}<0.01)$ & &
\end{tabular}


Table 7. Key managerial characteristics by farm-size categories

\begin{tabular}{|c|c|c|c|c|}
\hline \multirow{2}{*}{$\begin{array}{l}\text { Managerial } \\
\text { characteristics }\end{array}$} & \multicolumn{3}{|c|}{ Farm size categories } & \multirow{2}{*}{$\begin{array}{l}\text { F-test }{ }^{\mathrm{a}} \text { of } \\
\text { differences } \\
\text { across farm } \\
\text { size categories }\end{array}$} \\
\hline & $\begin{array}{c}\text { Large farms } \\
(2.0 \text { ha and above })\end{array}$ & $\begin{array}{l}\text { Medium farms } \\
(1.01 \text { to }<2.0 \text { ha })\end{array}$ & $\begin{array}{l}\text { Small farms } \\
\text { (up to } 1.0 \text { ha) }\end{array}$ & \\
\hline $\begin{array}{l}\text { Education (competed } \\
\text { years of schooling) }\end{array}$ & 7.45 & 4.35 & 4.14 & $16.27 * * *$ \\
\hline $\begin{array}{l}\text { Wheat growing } \\
\text { experience (years) }\end{array}$ & 18.10 & 16.86 & 14.91 & $6.64 * * *$ \\
\hline $\begin{array}{l}\text { Timing of first } \\
\text { fertilization (index) }\end{array}$ & 1.08 & 1.13 & 1.33 & $9.72 * * *$ \\
\hline $\begin{array}{l}\text { Timing of first } \\
\text { weeding (index) }\end{array}$ & 3.62 & 3.21 & 3.15 & $3.61 * *$ \\
\hline $\begin{array}{l}\text { Number of irrigation } \\
\text { (nos.) }\end{array}$ & 1.83 & 1.49 & 1.40 & $9.17 * * *$ \\
\hline $\begin{array}{l}\text { Mechanical power } \\
\text { services }(\%)\end{array}$ & 0.78 & 0.62 & 0.54 & $5.28 * * *$ \\
\hline $\begin{array}{l}\text { Number of mechanical } \\
\text { ploughing (nos.) }\end{array}$ & 3.47 & 2.84 & 2.47 & $6.92 * * *$ \\
\hline $\begin{array}{l}\text { Sources of agricultural } \\
\text { information (nos.) }\end{array}$ & 2.23 & 2.08 & 2.07 & 0.66 \\
\hline $\begin{array}{l}\text { Training in wheat } \\
\text { production }(\%)\end{array}$ & 0.22 & 0.15 & 0.11 & $2.36^{*}$ \\
\hline $\begin{array}{ll}\text { Note: } & { }^{\mathrm{a}}=\text { One-way ANO } \\
& * * * \text { significant at } 1 \\
& * * \text { significant at } 5 \mathrm{p} \\
& * \text { significant at } 10 \mathrm{p}\end{array}$ & $\begin{array}{l}\text { VA using the Generalise } \\
\text { percent level }(\mathrm{p}<0.01) \\
\text { percent level }(\mathrm{p}<0.05) \\
\text { percent level }(\mathrm{p}<0.10)\end{array}$ & Linear Model (GLM) & & \\
\hline
\end{tabular}




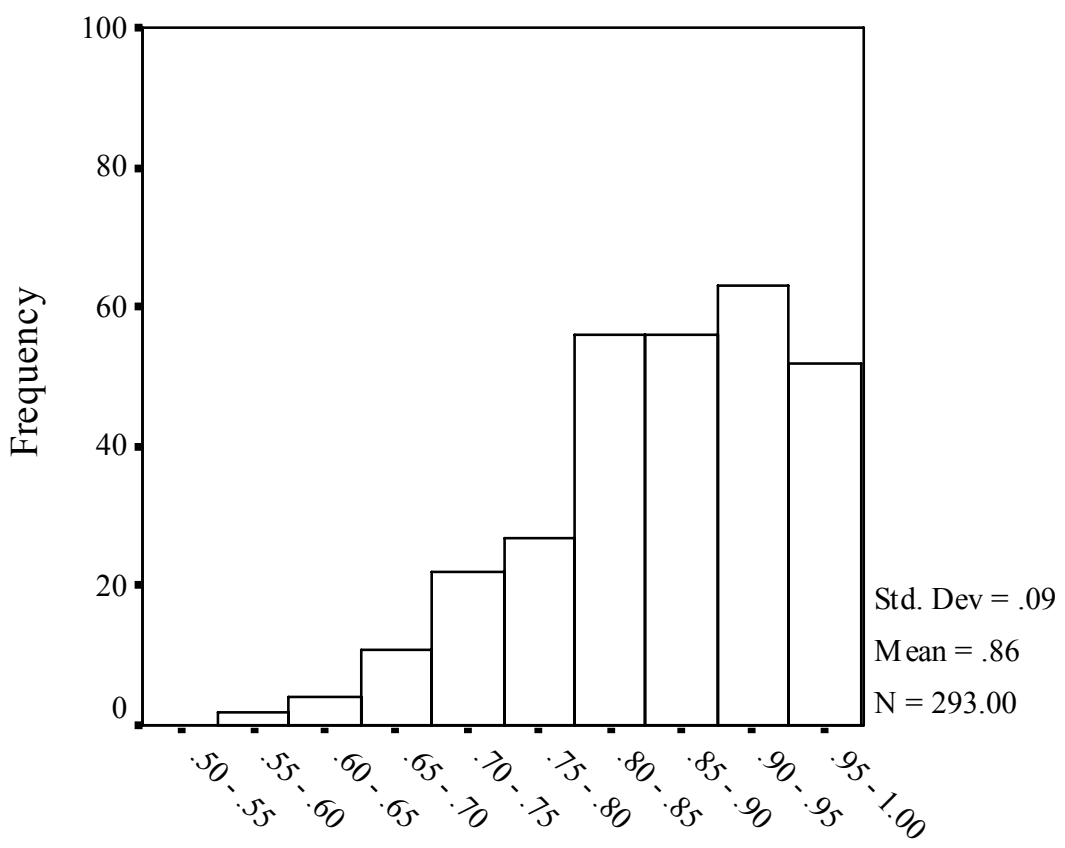

Technical efficiency (without environmental variables)

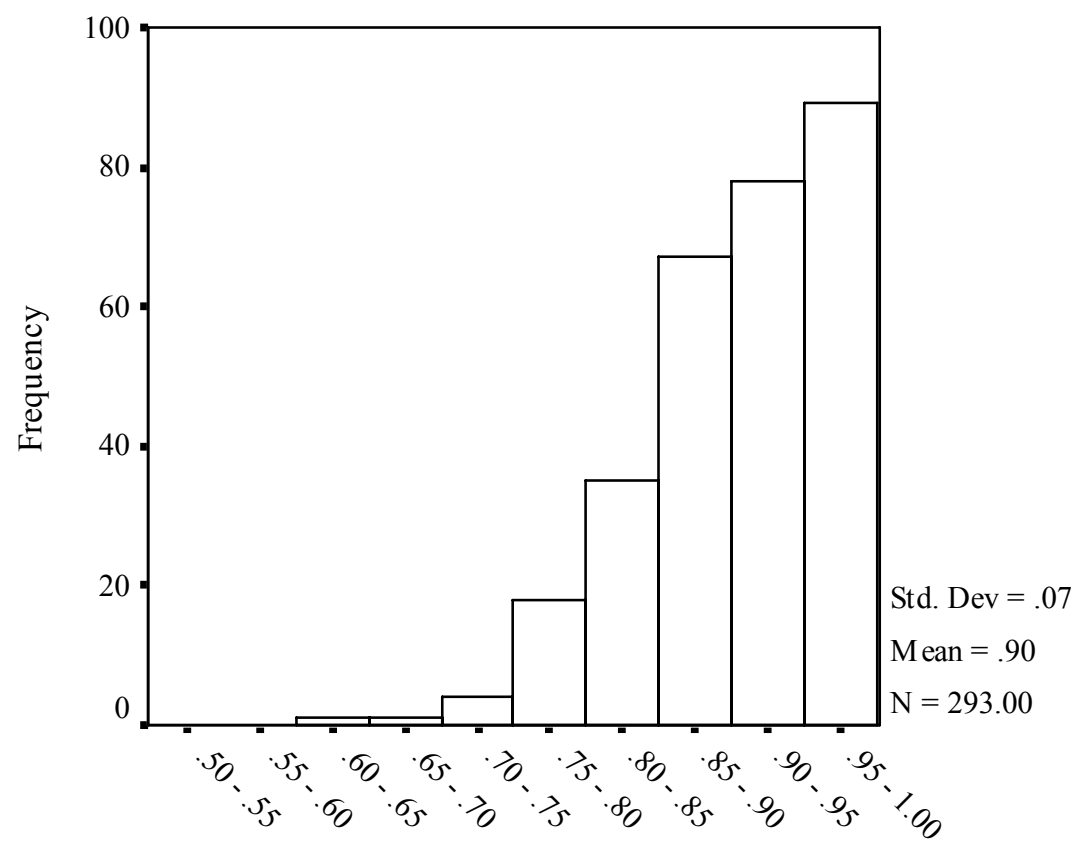

Technical efficiency (with environmental variables)

Figure 1. Technical efficiency scores under short and full specifications 